\title{
Psychological Resilience and Health-Related Quality of Life in Swedish Women with Newly Diagnosed Breast Cancer
}

This article was published in the following Dove Press journal: Cancer Management and Research

\author{
Åsa Mohlin (i) ${ }^{1,2}$ \\ Ulrika Axelsson ${ }^{3}$ \\ Pär-Ola Bendahl ${ }^{4}$ \\ Carl Borrebaeck (iD) ${ }^{3}$ \\ Cecilia Hegardt ${ }^{4}$ \\ Per Johnsson ${ }^{5}$ \\ Ingalill Rahm Hallberg ${ }^{6}$ \\ Lisa Rydén $\mathbb{1}^{7,8}$
}

'Department of Clinical Sciences Lund, Division of Medical History, Lund University, Lund 22I 84, Sweden;

${ }^{2}$ Healthcare Center Laröd, Helsingborg 252 86, Sweden; ${ }^{3}$ Department of Immunotechnology and CREATE Health Translational Cancer Center, Lunds University, Lund 223 8I, Sweden; ${ }^{4}$ Department of Clinical Sciences Lund, Division of Oncology and Pathology, Lund University, Lund 223 8I, Sweden;

${ }^{5}$ Department of Psychology, Lund University, Lund 221 00, Sweden;

${ }^{6}$ Department of Health Sciences, Lund University, Lund 221 00, Sweden;

${ }^{7}$ Department of Clinical Sciences Lund, Division of Surgery, Lund University, Lund 223 81, Sweden; ${ }^{8}$ Department of Surgery, Skåne University Hospital, Malmö, 214 28, Sweden
Correspondence: Åsa Mohlin Healthcare Center Laröd, Travvägen 27, Helsingborg 252 86, Sweden Tel +46 42-406 0850

Email asa.mohlin@med.lu.se
Purpose: Psychological resilience appears to be an important influencing factor in various aspects of health-related quality of life (HRQoL) in a context of adversity, eg, being informed of a cancer diagnosis. The purpose was to investigate psychological resilience and HRQoL in Swedish women with newly diagnosed breast cancer in relation to demographic and clinicopathological characteristics.

Methods: A population-based cross-sectional study was conducted including 517 women with breast cancer in the South Swedish Health Care Region. Participants were enrolled at the time of consultation for the diagnosis. Psychological resilience was assessed with the Connor-Davidson Resilience Scale 25 (CD-RISC25), and HRQoL was assessed with the Short Form Health Survey. The participants responded to questions regarding demographic variables. Clinicopathological data were collected from the Swedish National Quality Register for Breast Cancer.

Results: The mean score for psychological resilience was 70.6 , identifying $15 \%$ of included patients with a score lower than 58 ( -1 standard deviation). The study cohort had significantly lower mean scores for several aspects of HRQoL compared with Swedish normative data. Regression analyses demonstrated that psychological resilience was significantly associated with all domains of HRQoL after adjustment for demographic and clinicopathological factors.

Conclusion: Higher levels of psychological resilience were significantly related to higher levels of HRQoL in Swedish women with newly diagnosed breast cancer and no modifying factor was identified. The assessment of psychological resilience at the time of breast cancer diagnosis might allow for early identification of women in need of more intense psychosocial support. Future studies are needed to identify a clinically relevant threshold of the CDRISC25.

Keywords: breast cancer, psychological resilience, health-related quality of life, ConnorDavidson Resilience Scale 25, CD-RISC25, Short Form Health Survey, SF-36

\section{Introduction}

Breast cancer (BC) is the most prevalent cancer in women in the Western world. ${ }^{1}$ Although the prognosis has dramatically improved, receiving a $\mathrm{BC}$ diagnosis means emotional turmoil for most patients, and it affects all aspects of health. ${ }^{2-6}$ Previous studies have shown that BC has a major impact on women's health-related quality of life (HRQoL) when measured by valid instruments, eg, the European Organization for Research and Treatment of Cancer Quality of Life Questionnaire (EORTC-QLQ), the 
Functional Assessment of Cancer Therapy Breast Cancer (FACT-B) and the Short Form Health Survey (SF-36). ${ }^{3}$ As the incidence of $\mathrm{BC}$ increases and survivors live longer, HRQoL has become an increasingly important outcome measure for BC patient. ${ }^{2-6}$ There has been a growing interest in determining the psychological factors that may enhance HRQoL in BC patients. ${ }^{4-7}$ Psychological resilience, defined as the capacity to cope successfully with external stress, eg, a diagnosis of cancer, has been described as the most important protective factor associated with $\mathrm{HRQoL}$ in $\mathrm{BC}$ patients. ${ }^{4,6,8-11}$ Higher levels of psychological resilience do not make the patients unaffected by distress, but they do help the patients to adapt when facing significant adversities. ${ }^{12-14}$ In studies including BC patients, higher levels of psychological resilience have been found to be associated with higher levels of HRQoL. ${ }^{4,8,10}$

The Connor-Davidson Resilience Scale 25 (CDRISC25) is one of the resilience scales that has been demonstrated to have the best psychometric properties and is the most commonly and widely used resilience scale. ${ }^{15-17}$ Prior BC studies using the CD-RISC25 are limited, and the reported mean scores on the CD-RISC25 (range 0-100) vary between 54.7 and 74.7. ${ }^{8,12,18-21}$ These studies are characterized by smaller sample sizes $(\mathrm{N}=98-253)$ and/ or different time points of assessment, ranging from the time of diagnosis to several years postdiagnosis, making it difficult to draw any firm conclusions. Importantly, only one published study has so far reported a defined time-point for assessment of psychological resilience. ${ }^{13}$

To enhance the life situation of patients in severe distress, such as women with newly diagnosed BC, a deeper understanding of psychological factors that are positively associated with HRQoL, including psychological resilience, is needed. Psychological resilience is assumed to be a dynamic and developmental process, reflecting the patient's ability to effectively adapt and adjust to difficult life situations and thereby maintain HRQoL in these situations. ${ }^{11}$ The assessment of psychological resilience at the time of $\mathrm{BC}$ diagnosis might allow for early identification of women in need of more intense psychosocial support across the cancer trajectory.

The present study included 517 Swedish women with newly diagnosed $\mathrm{BC}$ at the same time point of the cancer trajectory. The SF-36 was used in the present study to assess HRQoL and the CD-RISC25 to measure psychological resilience. ${ }^{16,22}$ To the best of our knowledge, this is one of the largest population-based cross-sectional studies published to date worldwide concerning the relationship between psychological resilience and HRQoL at the time of diagnosis in women with primary $\mathrm{BC}^{22}$

The purpose of the study was (a) to investigate psychological resilience, as measured by the CD-RISC25, at the time of $\mathrm{BC}$ diagnosis, (b) to investigate HRQoL, as measured by the SF-36, at the time of BC diagnosis and (c) to investigate the association between psychological resilience and HRQoL in relation to demographic and clinicopathological characteristics in Swedish women with newly diagnosed $\mathrm{BC}$. We hypothesized that higher levels of psychological resilience would be associated with higher levels of HRQoL in the study cohort.

\section{Materials and Methods}

\section{Study Design and Study Cohort}

This cross-sectional study was conducted within the greater prospective study SCAN-B Resilience (NCT03430492) ${ }^{7}$ as part of the Sweden Cancerome Analysis Network - Breast (SCAN-B) initiative. ${ }^{23}$ The inclusion criteria for SCAN-B Resilience have been stated in the published study protocol. ${ }^{7}$ SCAN-B Resilience briefly includes all newly diagnosed patients with primary in situ or invasive cancer, consecutively included at the study centres. Study-specific inclusion and exclusion criteria for the present study are presented in Figure 1. In this study, patients with bilateral cancer were excluded due to incongruent register data.

The SCAN-B is a large population-based study that includes almost $90 \%$ of all new BC patients from southern Sweden (NCT02306096). ${ }^{23,24}$ The SCAN-B cohort has good representativity in comparison to all women with BC reported in the Swedish National Quality Registry for Breast Cancer (NKBC) during the same time period. ${ }^{25}$ Patients enrolled in SCAN-B at Blekinge County Hospital, Central Hospital Växjö, Hallands Hospital Halmstad and Helsingborgs Hospital were also invited to be enrolled in SCAN-B Resilience. Karlskrona (Blekinge), Växjö, Halmstad and Helsingborg are urban cities; however, Karlskrona, Växjö and Halmstad have more rural areas than Helsingborg. Helsingborg is a larger, multi-cultural city that was included in SCAN-B Resilience at a later stage.

In all, 607 Swedish women with primary BC diagnosed between February 2016 and September 2018 were included in SCAN-B Resilience. A total of 517 patients with complete assessments (CD-RISC25 and SF-36) and NKBC data (clinicopathological variables) were selected for this cross-sectional study (Figure 1). The participants 


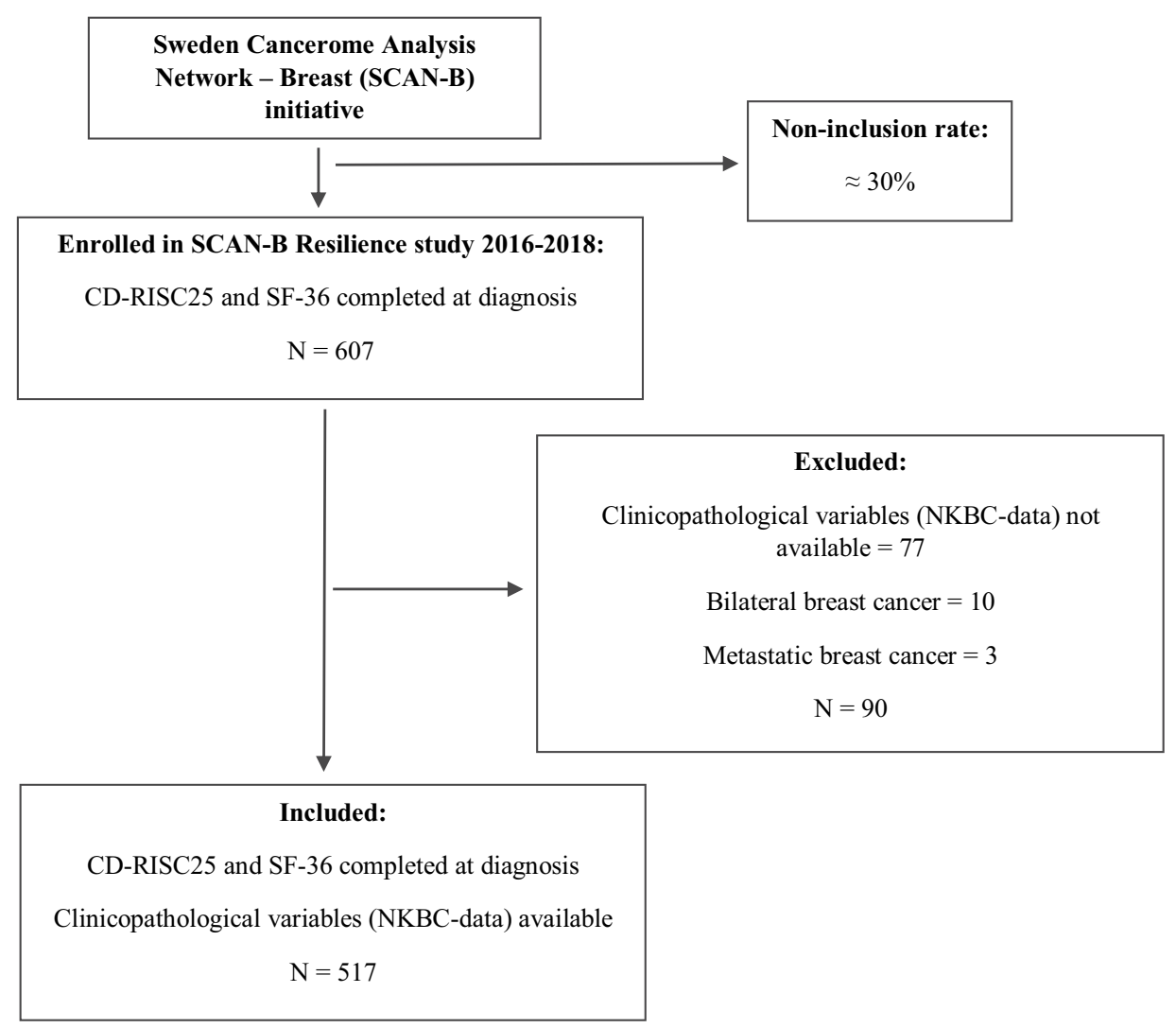

Figure I Flow chart of the study cohort.

were enrolled at the time they were informed of the $\mathrm{BC}$ diagnosis at Blekinge County Hospital $(\mathrm{N}=149)$, Central Hospital Växjö $(\mathrm{N}=175)$, Hallands Hospital Halmstad $(\mathrm{N}=163)$ and Helsingborgs Hospital $(\mathrm{N}=30)$. The diagnostic work-up was performed approximately two to three weeks before the visit to the Breast Unit and included mammography, ultrasound and biopsy.

The inclusion rate of the present study was estimated to be nearly 70\%. Approximately one-third of those not included gave no specific reasons for not wanting to participate. Another one-third declined to participate because of limitations due to physical or mental problems; eg, some reported experiencing too much stress or shock after the diagnosis. For the remaining third, the reasons were more varied, eg, language problems or a lack of time.

The patients were given oral and written information about SCAN-B Resilience by BC nurses after consenting to participate in SCAN-B. Written consent for the present SCAN-B Resilience study was provided before the participants completed the assessments. The participants completed the assessments before leaving the Breast Units after the cancer consultation at which they were informed about the diagnosis and the treatment plan. The participants completed the assessments electronically or on paper.

SCAN-B and SCAN-B Resilience were approved by the Ethics Committee at Lund University (Dnr 2009/658, 2010/383, 2012/58, 2013/459, 2015/277, 2015/522, 2016/ 944, 2017/875). The approval included access to NKBC data and administration of the questionnaires.

\section{Instruments}

Social network, educational level and financial situation data were collected by questions added to the standardized instruments. The questions about educational level and financial situation are commonly used in Swedish population studies. ${ }^{26}$ The question about social network was designed for the SCAN-B Resilience study and aimed to capture the presence of adults or children living in the same or separate households with whom the participant has an ongoing relationship.

Information on age, menstrual status, mode of detection, stage of $\mathrm{BC}$, type of $\mathrm{BC}$ and primary therapy was collected from the NKBC register, which holds information on almost $100 \%$ of Swedish women diagnosed with $\mathrm{BC}$ since 2008 . $^{25}$ 
Psychological resilience was measured with the CDRISC25. ${ }^{15,16}$ The Swedish version of the instrument was used; it was obtained from its author, who gave permission for its use. The instrument consists of 25 items that are ranked on a Likert scale from 0 to 4 points, from "Not true at all" to "True nearly all the time". Examples of items are "Able to adapt to change", "Think of self as strong person" and "Tend to bounce back after illness or hardship". The full range of the scale is $0-100$ points. Higher scores reflect greater psychological resilience. The CD-RISC25 has shown good validity and reliability in previous studies in which psychological resilience has been measured in different populations and in relation to different health problems, including BC. ${ }^{15-17}$ In the CD-RISC Manual, results of studies using the scale are presented. ${ }^{16}$ Cronbach's alpha of the CD-RSC25 has in previous BC studies varied between 0.89 and $0.95 .^{8,12,13,20,21}$ Recently a Swedish population-based study has been published, where the mean score for psychological resilience was reported to 68.7 among women in a non-clinical population $(\mathrm{N}=1283$, Cronbach's alpha $=0.92) .{ }^{14}$ This non-clinical population was selected based on reaching out for people with lung- and heart diseases. Thus, Swedish norm data are not yet available. Connor and Davidson, in their original study, reported a mean score of 80.4 for psychological resilience in a US general population $(\mathrm{N}=577) .{ }^{15}$ Cronbach 's alpha of the CD-RISC25 was 0.91 in the present study.

The Swedish version of the SF-36 was used to assess HRQoL. ${ }^{22}$ The instrument consists of 36 items that are ranked on scales of varying types. Examples of items are "Compared to one year ago, how would you rate your health in general now?" and

During the past 4 weeks, to what extent has your physical health or emotional problems interfered with your normal social activities with family, friends, neighbours, or groups?

The 36 items are grouped into eight domains: physical functioning $(\mathrm{PF})$, role limitations due to physical problems (RP), bodily pain (BP), general health (GH), vitality (VT), social functioning (SF), role limitations due to emotional problems (RE) and mental health (MH). The items are recoded in the domains to scores between 0 and 100 , where 0 represents the worst HRQoL and 100 the best HRQoL. The Swedish version of the SF-36 has been proven to be a valid and reliable instrument. ${ }^{22,27,28}$ Swedish norm data are available. ${ }^{22}$ Permission to use the SF-36 was obtained from Optum (Optum Circle, Eden Prairie, MN USA). Cronbach's alpha of the SF-36 was 0.86 in this study.

\section{Statistics}

Percentage, mean and standard deviation (SD) were calculated for the demographic variables, clinicopathological variables, and CD-RISC25 and SF-36 scores. The median was also calculated for age. Independent-samples $t$-tests were used to compare two groups, and one-way analysis of variance was used to compare three or more groups for the comparisons of the CD-RISC25 scores to different demographic and clinicopathological variables. Independent-samples $t$-test was also used to compare the mean SF-36 scores across the study cohort with Swedish normative data. Pearson correlation coefficient analyses were used to investigate the association between the CD-RISC25 and the SF-36. Uni- and multivariable linear regression analyses were conducted to explore the relationship between the CD-RISC25 (independent variable) and each of the eight domains of SF-36 (dependent variables). Potential confounders were investigated in these analyses by adjusting for demographic and clinicopathological variables in the multivariable regression models.

Model diagnostics were performed and revealed no deviations questioning the use of independent-samples $t$-test and one-way analysis of variance when comparing the distribution of the CD-RISC25 scores in subgroups of patients based on demographic and clinicopathological variables. Non-normality of residuals was, however, seen to a varying degree for the linear regression models with domains of the SF-36 as outcome, but robust strong evidence for positive correlation between CD-RISC25 and each of the 8 domains' SF-36 was seen also in nonparametric analyses. Hence, the relative sizes of the slopes presented mirror the strength of the relationships, but the sizes of the regression coefficients should be interpreted with caution.

P-values $<0.05$ were considered statistically significant, but because no adjustment for multiple testing was performed, some caution is warranted when interpreting the level of evidence for a specific test. The statistical analyses were conducted using the Statistical Package for the Social Sciences (SPSS) version 25.0 (IBM, Armonk, NY, USA).

\section{Results \\ Study Cohort}

The median age of the women was 64 years (range 31-89), $81 \%$ were postmenopausal, $52 \%$ were diagnosed with stage I BC and $91 \%$ had invasive $\mathrm{BC}$ (Table 1). In $65 \%$, BC was 
Table I Mean Scores of Psychological Resilience (CD-RISC25) According to Clinicopathological and Demographic Characteristics $(\mathrm{N}=517)$

\begin{tabular}{|c|c|c|c|c|c|c|}
\hline \multirow[t]{2}{*}{ Variables } & & \multirow[t]{2}{*}{$\mathbf{N}$} & \multirow[t]{2}{*}{$\%$} & \multicolumn{3}{|c|}{ CD-RISC25 } \\
\hline & & & & Range & Mean (SD) & $P$-value ${ }^{a}$ \\
\hline All participants & & & & $31-100$ & $70.6(12.7)$ & \\
\hline Age (years) & $\begin{array}{l}\text { Mean (SD): } 62 \pm \mathrm{II} \\
\leq 64 \text { (median) } \\
>64 \text { (median) }\end{array}$ & $\begin{array}{l}269 \\
248\end{array}$ & $\begin{array}{l}52 \\
48\end{array}$ & $\begin{array}{l}34-100 \\
31-100\end{array}$ & $\begin{array}{l}71.3(12.4) \\
70.0(13.0)\end{array}$ & 0.239 \\
\hline Menstrual status & $\begin{array}{l}\text { Premenopausal } \\
\text { Postmenopausal } \\
\text { Unknown }\end{array}$ & $\begin{array}{l}93 \\
397 \\
27\end{array}$ & $\begin{array}{l}19 \\
81\end{array}$ & $\begin{array}{l}46-100 \\
31-100\end{array}$ & $\begin{array}{l}74.0(11.7) \\
69.8(12.7)\end{array}$ & 0.005 \\
\hline Stage of breast cancer & $\begin{array}{l}0 \\
\text { I } \\
\text { II } \\
\text { III } \\
\text { Unknown }\end{array}$ & $\begin{array}{l}43 \\
269 \\
164 \\
39 \\
2\end{array}$ & $\begin{array}{l}8 \\
52 \\
32 \\
8\end{array}$ & $\begin{array}{l}3 I-96 \\
34-100 \\
4 I-96 \\
4 I-97\end{array}$ & $\begin{array}{l}69.5(12.8) \\
69.8(13.1) \\
71.4(11.5) \\
73.9(13.6)\end{array}$ & 0.196 \\
\hline Type of cancer & $\begin{array}{l}\text { Carcinoma in situ } \\
\text { Invasive cancer } \\
\text { Unknown }\end{array}$ & $\begin{array}{l}46 \\
450 \\
21\end{array}$ & $\begin{array}{l}9 \\
91\end{array}$ & $\begin{array}{l}31-96 \\
34-100\end{array}$ & $\begin{array}{l}69.6(13.0) \\
70.6(12.7)\end{array}$ & 0.620 \\
\hline Mode of detection & $\begin{array}{l}\text { Screening } \\
\text { Symptomatic } \\
\text { Unknown }\end{array}$ & $\begin{array}{l}334 \\
182 \\
1\end{array}$ & $\begin{array}{l}65 \\
35\end{array}$ & $\begin{array}{l}34-100 \\
31-100\end{array}$ & $\begin{array}{l}69.9(12.4) \\
72.0(13.0)\end{array}$ & 0.084 \\
\hline Primary therapy & $\begin{array}{l}\text { Surgery } \\
\text { Systemic therapy }\end{array}$ & $\begin{array}{l}491 \\
26\end{array}$ & $\begin{array}{l}95 \\
5\end{array}$ & $\begin{array}{l}31-100 \\
56-92\end{array}$ & $\begin{array}{l}70.5(12.8) \\
73.7(9.7)\end{array}$ & 0.201 \\
\hline Study site & $\begin{array}{l}\text { Halmstad } \\
\text { Helsingborg } \\
\text { Karlskrona } \\
\text { Växjö }\end{array}$ & $\begin{array}{l}163 \\
30 \\
149 \\
175\end{array}$ & $\begin{array}{l}31 \\
6 \\
29 \\
34\end{array}$ & $\begin{array}{l}34-100 \\
36-100 \\
31-100 \\
36-99\end{array}$ & $\begin{array}{l}70.1 \text { (I3.I) } \\
73.8(14.5) \\
71.1(12.6) \\
70.2(12.0)\end{array}$ & 0.464 \\
\hline Social network & $\begin{array}{l}\text { Living alone } \\
\text { Living with child/children }<18 \text { years old only } \\
\text { Living with adult/adults and child/children }<18 \text { years old } \\
\text { Living with adult/adults only }\end{array}$ & $\begin{array}{l}114 \\
11 \\
65 \\
327\end{array}$ & $\begin{array}{l}22 \\
2 \\
13 \\
63\end{array}$ & $\begin{array}{l}31-100 \\
46-91 \\
51-100 \\
34-100\end{array}$ & $\begin{array}{l}72.0(12.1) \\
74.4(11.7) \\
75.4(11.4) \\
69.1(12.9)\end{array}$ & 0.001 \\
\hline Educational level & $\begin{array}{l}\text { Primary school }<9 \text { years } \\
\text { Primary school completed } \\
\text { Upper secondary education } \\
\text { Post-secondary education }<2 \text { years } \\
\text { Post-secondary education } \geq 2 \text { years } \\
\text { PhD (doctoral education) }\end{array}$ & $\begin{array}{l}70 \\
74 \\
92 \\
66 \\
204 \\
11\end{array}$ & $\begin{array}{l}14 \\
14 \\
18 \\
13 \\
39 \\
2\end{array}$ & $\begin{array}{l}3 I-100 \\
4 I-97 \\
4 I-97 \\
36-100 \\
36-100 \\
4 I-92\end{array}$ & $\begin{array}{l}70.9(14.6) \\
69.3(13.6) \\
70.8(11.7) \\
70.0(12.3) \\
71.0(12.1) \\
75.5(15.2)\end{array}$ & 0.734 \\
\hline Financial situation & $\begin{array}{l}\text { Able to pay an unexpected bill of SEK II,000/EUR II } 00 \\
\text { Unable to pay an unexpected bill of SEK II,000/EUR II } 00\end{array}$ & $\begin{array}{l}466 \\
51\end{array}$ & $\begin{array}{l}90 \\
10\end{array}$ & $\begin{array}{l}34-100 \\
31-100\end{array}$ & $\begin{array}{l}70.8(12.5) \\
68.9(14.3)\end{array}$ & 0.300 \\
\hline
\end{tabular}

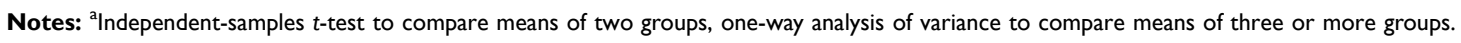

detected within a screening programme. Most patients (95\%) planned to undergo surgery as primary therapy, whereas $5 \%$ planned to neoadjuvant therapy. Regarding demographic variables, $63 \%$ of the women were living with an adult/ adults, 22\% were living alone, $13 \%$ were living with an adult/adults and a child/children under 18 years, and $2 \%$ were living with a child/children only. In addition, $39 \%$ had more than two years of post-secondary education, and $90 \%$ answered yes to the question about their ability to pay an unexpected bill of SEK 11,000/EUR 1100. 


\section{Psychological Resilience}

The mean score for psychological resilience was 70.6 (SD \pm 12.7 ) (Figure 2). As depicted in Figure 2, 70\% of the women in the cohort had a level of psychological resilience within $1 \mathrm{SD}$ of the mean score. Approximately $15 \%$ of the women had a level of psychological resilience lower than 58 ( $1 \mathrm{SD}$ below the mean score). Scores for psychological resilience were significantly higher in premenopausal women than in postmenopausal women $(P=0.005)$ (Table 1). Women who lived with a child/children but with or without an adult/adults had significantly higher psychological resilience than women who lived alone or with an adult/adults only $(P=0.001)$. None of the other demographic and clinicopathological variables included were significantly related to the CD-RISC25 score.

\section{Health-Related Quality of Life}

The study cohort had significantly lower mean scores for several aspects of HRQoL compared with Swedish normative data (Table 2). Except for VT $(P=0.780)$, the psychological domains of the SF-36; SF, RE and MH $(P<0.001)$, were lower in the study cohort than in the normative sample. Among the physical domains of the SF-36; GH $(P<0.001)$ scores were significantly lower in the study cohort. The mean score for BP $(P<0.001)$ was significantly higher, indicating lower levels of pain in the study cohort compared to the normative data. For PF $(P=0.056)$ and RP $(P=0.846)$, there were no significant differences across the cohorts.

\section{Correlation Between Psychological Resilience and Health-Related Quality of} Life

Pearson's correlation coefficient analyses presented positive correlations between the CD-RISC25 and all eight domains of the SF-36 (Table 3). The correlations ranged between 0.20 and 0.37 , indicating a low to moderate correlation between psychological resilience and all domains of HRQoL $(P<0.001)$.

\section{Uni- and Multivariable Linear Regression Analyses Between Psychological Resilience and Health-Related Quality of Life}

Psychological resilience was found to be significantly associated with each of the eight domains of HRQoL $(P<0.001)$. Unadjusted models and models adjusted for

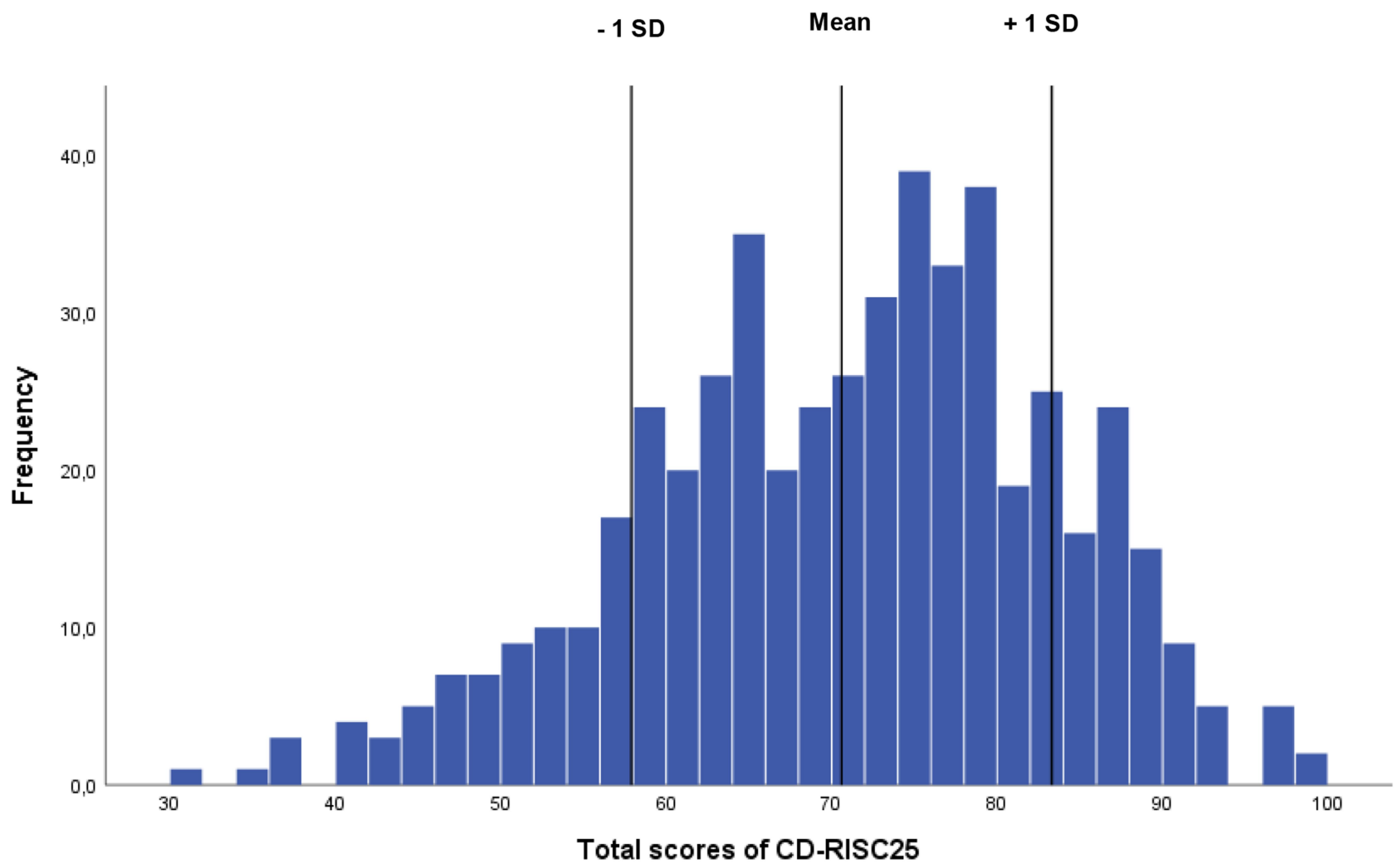

Figure 2 Histogram of total scores for psychological resilience (CD-RISC25) $(\mathrm{N}=517)$. 
Table 2 Health-Related Quality of Life (SF-36) $(\mathrm{N}=517)$

\begin{tabular}{|c|c|c|c|}
\hline Variables & $\begin{array}{l}\text { Study } \\
\text { Cohort: } \\
\text { Mean } \\
\text { (SD) }\end{array}$ & $\begin{array}{l}\text { Norm: } \\
\text { Mean } \\
\text { (SD) }\end{array}$ & $\begin{array}{l}\text { P-values for } \\
\text { Differences } \\
\text { Between Study } \\
\text { Cohort and } \\
\text { Norm Data for } \\
\text { SF-36 }\end{array}$ \\
\hline SF-36 & & & \\
\hline $\begin{array}{l}\text { Physical } \\
\text { functioning }\end{array}$ & $84.4(19.4)$ & $86.2(20.4)$ & 0.056 \\
\hline Role-physical & $81.3(34.7)$ & $81.6(33.1)$ & 0.846 \\
\hline Bodily pain & $80.8(20.9)$ & $72.7(26.5)$ & $<0.001$ \\
\hline General health & $70.2(19.4)$ & 75.1 (22.7) & $<0.001$ \\
\hline Vitality & $67.0(23.1)$ & 66.7 (23.2) & 0.780 \\
\hline Social functioning & $83.9(22.4)$ & $87.5(20.8)$ & $<0.001$ \\
\hline Role-emotional & $76.6(36.7)$ & $84.0(30.9)$ & $<0.001$ \\
\hline Mental health & $70.1(21.5)$ & $79.6(19.4)$ & $<0.001$ \\
\hline
\end{tabular}

Note: ${ }^{a}$ Independent-samples $t$-test to compare means of two groups.

Table 3 Correlations Between Psychological Resilience (CDRISC25) and Health-Related Quality of Life (SF-36) ( $N=517)$

\begin{tabular}{|l|l|}
\hline Variables & CD-RISC25 \\
\hline SF-36 & Pearson Correlation Coefficient*** \\
\hline Physical functioning & 0.21 \\
Role-physical & 0.20 \\
Bodily pain & 0.21 \\
General health & 0.37 \\
Vitality & 0.33 \\
Social functioning & 0.27 \\
Role-emotional & 0.26 \\
Mental health & 0.34 \\
\hline
\end{tabular}

Note: ***P-value $<0.001$ for all correlation coefficients.

demographic and clinicopathological factors are presented in Table 4. Variables which were significantly associated with psychological resilience and clinically relevant variables, consisting of social network, menstrual status, age, mode of detection and stage of breast cancer, were included in the regression models. The Beta coefficients for the CD-RISC25, one per SF-36 domain, ie, the expected change in HRQoL associated with one unit change in psychological resilience, did not change substantially after multivariable adjustment indicating that the unadjusted models were not confounded by the adjustment variables.

\section{Discussion}

To the best of our knowledge, this is the first time data from a population-based consecutive cross-sectional
Swedish study cohort has been used to show that psychological resilience is associated with HRQoL in women with newly diagnosed $\mathrm{BC}$. The study indicates that at the time of receiving the diagnosis, both psychological resilience and HRQoL scores are lower than those based on population data.

The results are consistent with the findings of prior studies $^{8,12,18-21}$ demonstrating the possible need for psychosocial support of BC patients as most of the women presented lower levels of psychological resilience compared to normative data reported by Connor and Davidson. ${ }^{15}$ The present study included a cohort of 517 Swedish women with a mean psychological resilience score of 70.6 at the time of diagnosis. The mean CDRISC25 score varied between 54.7 and 74.7 in earlier studies. ${ }^{8,12,18-21}$ Markovitz et al reported higher levels of psychological resilience, 93.8, compared to other $\mathrm{BC}$ studies. ${ }^{13}$ However, they used a 1- to 5-point Likert scale instead of the recommended 0 - to 4-point Likert scale. ${ }^{15,16}$ On the website of the CD-RISC25 authors, ${ }^{16}$ the mean score for the $\mathrm{BC}$ cohort in the study by Markovitz et al was recalculated to 68.8 , which is close to the mean score in this study.

As psychological resilience is assumed to be a dynamic process, minor variations across $\mathrm{BC}$ studies can be explained by differences in the timing of the CD-RISC 25 assessment. $^{12,29}$ The time span from diagnosis to CDRISC25 assessment differs widely in the reported studies. ${ }^{8,12,18,19}$ This indicates that some women were affected by events linked to the treatment, while others more or less had recovered their levels of psychological resilience at the time they completed the CD-RISC25. In contrast, all patients in the present study were included at the same time point, but may already have been affected by the diagnostic work-up for suspected BC. Although the information about diagnosis and treatment was given right before they responded to the instruments, it is reasonable to assume that they were aware at that time that something was wrong. The diagnostic work-up was conducted two to three weeks before the consultation, and the women were advised to bring someone close to them. Similarly, BC patients in previous studies scored even lower on psychological resilience when it was measured close to therapy. ${ }^{12,20,21}$ Other than the present study, Markovitz et al is the only $\mathrm{BC}$ study to report a distinct time of inclusion. ${ }^{13}$ In this Belgic BC cohort, psychological resilience was measured at the time of primary surgery, one to two weeks after the women had been informed of the 
Table 4 Uni- and Multivariable Linear Regression Analyses Between Psychological Resilience (CD-RISC25) and Health-Related Quality of Life (SF-36) $(\mathrm{N}=517)$

\begin{tabular}{|c|c|c|c|c|c|}
\hline & \multicolumn{3}{|c|}{ Model I - Unadjusted } & \multicolumn{2}{|c|}{ Model 2 - Adjusted ${ }^{a}$} \\
\hline & \multicolumn{3}{|c|}{ CD-RISC25 } & \multicolumn{2}{|c|}{ CD-RISC25 } \\
\hline & $\beta^{* * *}$ & $95 \% \mathrm{Cl}$ & $\mathbf{R}^{2}$ & $\beta^{* * *}$ & $95 \% \mathrm{Cl}$ \\
\hline Physical functioning & 0.320 & $0.190-0.449$ & 0.044 & 0.272 & $0.144-0.401$ \\
\hline Role-physical & 0.548 & $0.316-0.780$ & 0.040 & 0.490 & $0.250-0.730$ \\
\hline Bodily pain & 0.349 & $0.210-0.488$ & 0.045 & 0.315 & $0.169-0.461$ \\
\hline General health & 0.559 & $0.435-0.682$ & 0.134 & 0.599 & $0.473-0.763$ \\
\hline Vitality & 0.603 & $0.454-0.752$ & 0.109 & 0.609 & $0.454-0.763$ \\
\hline Social functioning & 0.474 & $0.327-0.622$ & 0.072 & 0.512 & $0.356-0.667$ \\
\hline Role-emotional & 0.760 & $0.518-1.002$ & 0.069 & 0.824 & $0.57 \mid-1.078$ \\
\hline Mental health & 0.581 & $0.443-0.719$ & 0.117 & 0.628 & $0.483-0.773$ \\
\hline
\end{tabular}

Notes: ${ }^{a}$ Adjusted for social network, menstrual status, age, mode of detection and stage of breast cancer. $* * *$-value $<0.00 \mathrm{I}$ for all $\beta$ coefficients. Abbreviations: $\beta$, beta coefficient; $95 \% \mathrm{Cl}, 95 \%$ confidence interval; $\mathrm{R}^{2}$, goodness-of-fit.

diagnosis, and the mean score is in line with the results of this study. Our results indicate that already at the time of the $\mathrm{BC}$ diagnosis, some women may need more intense psychosocial support because the levels of psychological resilience were lower than those based on population data. ${ }^{15}$

HRQoL (GH, SF, RE and MH) was lower in the investigated women compared with Swedish normative data. ${ }^{22}$ It is fair to assume, as with psychological resilience, that the fear of $\mathrm{BC}$ during the diagnostic work-up had already had an impact on the patients' HRQoL at the time of the diagnosis. Only a few of the previous BC studies have explored HRQoL in relation to psychological resilience, although they did not use the SF-36. ${ }^{8,10}$ Despite differences in the instruments chosen, the similarities between the results of our study and those of Ristevska-Dimitrovska et al and Zhang et al are a striking demonstration that higher levels of psychological resilience correspond to higher levels of HRQoL. ${ }^{8,10}$ In this study, significant correlations between the CD-RISC25 and all eight domains of the SF-36 were found. This agrees with findings reported by Ristevska-Dimitrovska et al that psychological resilience is correlated to most aspects of HRQoL in Macedonian BC patients. ${ }^{10}$ Additionally, Zhang et al showed that psychological resilience was correlated with HRQoL in a Chinese cohort. ${ }^{8}$ Using another measure for psychological resilience, Harms et al found an association between the Protective Factors for Resilience Scale (PFRS) and the SF-36 in a cancer cohort that included BC patients. ${ }^{4}$ Harms et al demonstrated that the correlations between the psychological domains of the SF-36 and the PFRS were stronger than the correlations between most of the physical domains of the SF-36. ${ }^{4}$ The results of this study are consistent with those of Harms et al as the strongest correlations in Swedish women were noted between the CDRISC25 and GH, followed by the psychological domains of the SF-36 (MH, VT, SF and RE).

The findings also indicate a significant relationship between psychological resilience and social network and menstrual status. Consequently, variables assumed to be related to psychological resilience, eg, social network, were included in the regression analyses. Wu et al ${ }^{12}$ investigated predictors of psychological resilience among Chinese women and found that age was negatively correlated with psychological resilience, which is in line with our finding that postmenopausal women had lower scores than premenopausal women. Similarly, Zhang et al, Huang et al and Alizadeh et al presented significant relationships between psychological resilience and social support/network in Chinese and Iranian women. ${ }^{8,20,21}$ The regression analyses in this study demonstrated that the CD-RISC was significantly associated with each of the eight domains of the SF-36 in terms of both unadjusted models and models adjusted for demographic and clinicopathological factors. Although psychological resilience was significantly regressed on all domains of the SF36 , the strongest impact of psychological resilience tended to be on GH and the psychological domains of the SF-36. Higher levels of psychological resilience can be considered to be a potential protective factor among Swedish BC patients for preserving their HRQoL in the context of adversity. Lower levels are a risk factor for emotional distress and impaired HRQoL. ${ }^{10,13,19}$

The mean score of 70.6 with a SD of 12.7 in the study cohort indicates that a fair share of the women included had a level of psychological resilience lower than 58 
(approximately $15 \%$ of the population). The application of a threshold of 58, which corresponds to less than $1 \mathrm{SD}$ below the mean score, may identify patients in need of psychosocial support at this early stage. The understanding that psychological resilience is associated with HRQoL in Swedish BC patients could be clinically important in the future development of rehabilitation interventions. Improved knowledge of this association would present an opportunity to develop evidence-based interventions for those presenting lower levels of psychological resilience at the time of $\mathrm{BC}$ diagnosis.

More knowledge on psychological resilience in Swedish women with BC is needed, such as Swedish normative data for the CD-RISC25. Longitudinal studies are required in which changes in psychological resilience can be observed over time. Qualitative studies are necessary to describe psychological resilience more extensively. Because of the cross-sectional design of the present study, causal relationships between psychological resilience and other variables of $\mathrm{BC}$ patients cannot be established. Further limitations are the non-inclusion rate of approximately $30 \%$. One reason women declined to take part in this study was experiencing too much stress after the BC diagnosis. It is possible that the most stressed patients might be the women with the lowest levels of psychological resilience, which could bias the results of this study towards patients with higher levels of psychological resilience. Information on comorbid conditions in the cohort, eg, coexisting emotional or mental disorders, was not available for the present study.

Although this study had limitations, it is one of the largest studies published to date regarding psychological resilience and HRQoL in BC patients. Another strength is the adjustment for other variables that may influence HRQoL in these women. Importantly, all patients were consecutively included at the time of diagnosis in the population-based SCAN-B study. ${ }^{23,24}$ Such early and coherent assessment of psychological resilience in relation to $\mathrm{BC}$ diagnosis has not been previously presented.

\section{Conclusions}

This population-based study is the first to investigate the association between psychological resilience and HRQoL in Swedish women with newly diagnosed BC. At the time of diagnosis, psychological resilience and HRQoL appear to be impaired in these women. Higher levels of psychological resilience were related to higher levels of HRQoL independent of demographic and clinicopathological characteristics, which demonstrates for the first time in a Swedish BC context that psychological resilience is an important independent psychological variable associated with HRQoL. The relevance of this association across the cancer trajectory needs to be further explored. The assessment of psychological resilience at the time of $\mathrm{BC}$ diagnosis might allow for the early identification of women in need of extended psychosocial support. The results of this study show that $15 \%$ of the patients had a level of psychological resilience lower than 58, which might be a putative level for stratifying patients for individualized rehabilitation to prevent impairment of HRQoL related to $\mathrm{BC}$ diagnosis.

\section{Abbreviations}

BC, Breast cancer; HRQoL, Health-related quality of life; SF-36, Short Form Health Survey; CD-RISC25, ConnorDavidson Resilience Scale 25; SCAN-B, Sweden Cancerome Analysis Network - Breast; NKBC, Swedish National Quality Registry for Breast Cancer; PF, Physical functioning; RP, Role limitations due to physical problems; BP, Bodily pain; GH, General health; VT, vitality; SF, Social functioning; RE, Role limitations due to emotional problems; MH, Mental health; SD, Standard deviation.

\section{Data Sharing Statement}

The datasets used and analyzed during the current study are available from the corresponding author on reasonable request.

\section{Ethics Approval and Informed Consent}

All procedures performed were in accordance with the ethical standards of the institutional research committee and with the 1964 Helsinki declaration and its later amendments or comparable ethical standards. Ethical approval was obtained from the Regional Ethics Committee at Lund University, Sweden (2009/658, 2010/ 383, 2012/58, 2013/459, 2015/277, 2015/522, 2016/944, 2017/875). Written informed consent was obtained from all individual participants included in the study.

\section{Acknowledgments}

We acknowledge the SCAN-B steering group, the SCANB Resilience study group, the Regional Cancer Center South and the South Swedish Breast Cancer Group for 
all their support. We thank all patients and personnel at the participating hospitals.

\section{Author Contributions}

All authors made a significant contribution to the work reported, whether that is in the conception, study design, execution, acquisition of data, analysis and interpretation, or in all these areas; took part in drafting, revising or critically reviewing the article; gave final approval of the version to be published; have agreed on the journal to which the article has been submitted; and agree to be accountable for all aspects of the work.

\section{Funding}

The study was supported by grants from the Birgit Rausing Donation, the Faculty of Medicine, Lund University, the Mats Paulsson Foundation, the Mrs Berta Kamprad Foundation, The Biltema Foundation and the CREATE Health Cancer Center.

\section{Disclosure}

Ulrika Axelsson reports grants from Dept of Immunotechnology, during the conduct of the study. The authors declare that they have no other potential conflicts of interest.

\section{References}

1. Ghoncheh M, Pournamdar Z, Salehiniya H. Incidence and mortality and epidemiology of breast cancer in the world. Asian Pac J Cancer Prev. 2016;17(S3):43-46. doi:10.7314/APJCP.2016.17.S3.43

2. Izci F, Sarsanov D, Erdogan ZI, et al. Impact of personality traits, anxiety, depression and hopelessness levels on quality of life in the patients with breast cancer. Eur J Breast Health. 2018;14(2):105-111.

3. Montazeri A. Health-related quality of life in breast cancer patients: a bibliographic review of the literature from 1974 to 2007. J Exp Clin Cancer Res. 2008;27(1):32.

4. Harms CA, Cohen L, Pooley JA, Chambers SK, Galvao DA, Newton RU. Quality of life and psychological distress in cancer survivors: the role of psycho-social resources for resilience. PsychoOncology. 2019;28(2):271-277. doi:10.1002/pon.4934

5. Karlsen RV, Frederiksen K, Larsen MB, et al. The impact of a breast cancer diagnosis on health-related quality of life. A prospective comparison among middle-aged to elderly women with and without breast cancer. Acta Oncol. 2016;55(6):720-727. doi:10.3109/0284186X. 2015.1127415

6. Zhang T, Li H, Liu A, Wang H, Mei Y, Dou W. Factors promoting resilience among breast cancer patients: a qualitative study. Contemp Nurse. 2018;54(3):293-303. doi:10.1080/10376178.2018.1502615

7. Axelsson U, Ryden L, Johnsson P, et al. A multicenter study investigating the molecular fingerprint of psychological resilience in breast cancer patients: study protocol of the SCAN-B resilience study. $B M C$ Cancer. 2018;18(1):789. doi:10.1186/s12885-018-4669-y

8. Zhang H, Zhao Q, Cao P, Ren G. Resilience and quality of life: exploring the mediator role of social support in patients with breast cancer. Med Sci Monit. 2017;23:5969-5979.
9. Haglund ME, Nestadt PS, Cooper NS, Southwick SM, Charney DS. Psychobiological mechanisms of resilience: relevance to prevention and treatment of stress-related psychopathology. Dev Psychopathol. 2007;19(3):889-920. doi:10.1017/S0954579407000430

10. Ristevska-Dimitrovska G, Filov I, Rajchanovska D, Stefanovski P, Dejanova B. Resilience and quality of life in breast cancer patients. Open Access Maced J Med Sci. 2015;3(4):727-731. doi:10.3889/ oamjms.2015.128

11. Alarcon R, Cerezo MV, Hevilla S, Blanca MJ. Psychometric properties of the Connor-Davidson resilience scale in women with breast cancer. Int J Clin Health Psychol. 2020;20(1):81-89. doi:10.1016/j. ijchp.2019.11.001

12. Wu Z, Liu Y, Li X, Li X. Resilience and associated factors among Mainland Chinese women newly diagnosed with breast cancer. PLoS One. 2016;11(12):e0167976. doi:10.1371/journal. pone. 0167976

13. Markovitz SE, Schrooten W, Arntz A, Peters ML. Resilience as a predictor for emotional response to the diagnosis and surgery in breast cancer patients. Psychooncology. 2015;24(12):1639-1645. doi:10.1002/pon.3834

14. Velickovic K, Rahm Hallberg I, Axelsson U, et al. Psychometric properties of the Connor-Davidson Resilience Scale (CD-RISC) in a non-clinical population in Sweden. Health Qual Life Outcomes. 2020;18(1):132. doi:10.1186/s12955-020-01383-3

15. Connor KM, Davidson JR. Development of a new resilience scale: the Connor-Davidson Resilience Scale (CD-RISC). Depress Anxiety. 2003;18(2):76-82. doi:10.1002/da.10113

16. The Connor-Davidson Resilience Scale. Available from: http://www. connordavidson-resiliencescale.com/. Accessed May 2020.

17. Windle G, Bennett KM, Noyes J. A methodological review of resilience measurement scales. Health Qual Life Outcomes. 2011;9(1):8. doi:10.1186/1477-7525-9-8

18. Fradelos EC, Papathanasiou IV, Veneti A, et al. Psychological distress and resilience in women diagnosed with breast cancer in greece. Asian Pac J Cancer Prev. 2017;18(9):2545-2550.

19. Ristevska-Dimitrovska G, Stefanovski P, Smichkoska S, Raleva M, Dejanova B. Depression and resilience in breast cancer patients. Open Access Maced J Med Sci. 2015;3(4):661-665. doi:10.3889/ oamjms.2015.119

20. Huang Y, Huang Y, Bao M, Zheng S, Du T, Wu K. Psychological resilience of women after breast cancer surgery: a cross-sectional study of associated influencing factors. Psychol Health Med. 2019;24(7):866-878. doi:10.1080/13548506.2019.1574353

21. Alizadeh S, Khanahmadi S, Vedadhir A, Barjasteh S. The relationship between resilience with self-compassion, social support and sense of belonging in women with breast cancer. Asian Pac J Cancer Prev. 2018;19(9):2469-2474.

22. Sullivan M, Karlsson J, Taft C, Ware JE. SF-36 Hälsoenkät: Svensk Manual Och Tolkningsguide $=($ Swedish Manual and Interpretation Guide). Göteborg: Sahlgrenska sjukhuset, Sektionen för vårdforskning; 2002.

23. Saal LH, Vallon-Christersson J, Hakkinen J, et al. The Sweden Cancerome Analysis Network - Breast (SCAN-B) initiative: a large-scale multicenter infrastructure towards implementation of breast cancer genomic analyses in the clinical routine. Genome Med. 2015;7(1):20. doi:10.1186/s13073-015-0131-9

24. Rydén L, Loman N, Larsson C, et al. Minimizing inequality in access to precision medicine in breast cancer by real-time population-based molecular analysis in the SCAN-B initiative. Br J Surg. 2018;105(2): e158-e168. doi:10.1002/bjs.10741

25. Swedish National Quality Registry for Breast Cancer (NKBC). Available from: https://www.cancercentrum.se/samverkan/cancerdiag noser/brost/kvalitetsregister/. Accessed May 2020.

26. Statistics Sweden. Surveys about living conditions (ULF/SILC). Available from: https://scb.se/. Accessed November 4, 2020. 
27. Sullivan M, Karlsson J, Ware JE Jr. The Swedish SF-36 health survey-I. Evaluation of data quality, scaling assumptions, reliability and construct validity across general populations in Sweden. Soc Sci Med. 1995;41(10):1349-1358. doi:10.1016/0277-9536(95)00125-Q

28. Sackey H, Sandelin K, Frisell J, Wickman M, Brandberg Y. Ductal carcinoma in situ of the breast. Long-term follow-up of health-related quality of life, emotional reactions and body image. Eur J Surg Oncol. 2010;36(8):756-762. doi:10.1016/j.ejso.2010.06.016
29. Dooley LN, Slavich GM, Moreno PI, Bower JE. Strength through adversity: moderate lifetime stress exposure is associated with psychological resilience in breast cancer survivors. Stress Health. 2017;33(5):549-557. doi:10.1002/smi.2739

\section{Publish your work in this journal}

Cancer Management and Research is an international, peer-reviewed open access journal focusing on cancer research and the optimal use of preventative and integrated treatment interventions to achieve improved outcomes, enhanced survival and quality of life for the cancer patient.
The manuscript management system is completely online and includes a very quick and fair peer-review system, which is all easy to use. Visit http://www.dovepress.com/testimonials.php to read real quotes from published authors. 